\title{
BMJ Open Hormone use among Nepali transgender women: a qualitative study
}

\author{
Pramod R Regmi, ${ }^{1}$ Edwin van Teijlingen, ${ }^{2}$ Sanjeev Raj Neupane, ${ }^{3}$ \\ Sujan Babu Marahatta ${ }^{4}$
}

To cite: Regmi PR, van Teijlingen E, Neupane SR, et al. Hormone use among Nepali transgender women: a qualitative study. BMJ Open 2019;9:e030464. doi:10.1136/ bmjopen-2019-030464

- Prepublication history for this paper is available online. To view these files, please visit the journal online (http://dx.doi. org/10.1136/bmjopen-2019030464).

Received 18 March 2019 Revised 06 September 2019 Accepted 30 September 2019

\section{Check for updates}

C Author(s) (or their employer(s)) 2019. Re-use permitted under CC BY-NC. No commercial re-use. See rights and permissions. Published by BMJ.

${ }^{1}$ Nursing and Clinical Sciences Bournemouth University, Bournemouth, UK

${ }^{2}$ Centre for Midwifery, Maternal \& Perinatal Health, Bournemouth University, Bournemouth, UK

${ }^{3}$ Save the Children, Kathmandu, Nepal

${ }^{4}$ Manmohan Memorial Institute of Health Sciences, Kathmandu, Nepal

Correspondence to Dr Pramod R Regmi pregmi@bournemouth.ac.uk

\begin{abstract}
Objectives There is a dearth of information on transgender individuals in Nepal, particularly studies exploring their use of hormone therapies. The objectives of this study therefore were to explore (1) how hormones are used, (2) types of hormones used and (3) side effects experienced by transgender women after hormone use. This is the first study of its kind in Nepal addressing this important public health issue.
\end{abstract}

Setting The study was conducted in four districts of Nepal: Kathmandu, Sunsai, Banke and Kaski.

Design and participants This qualitative study comprises eight focus group discussions (FGDs) and nine interviews. FGDs and three face-to-face interviews were held with transgender women aged 18 years and older and six interviews with stakeholders working with and advocating on behalf of this population. The study was conducted between September 2016 and March 2017.

Results Our participants were young. The majority of FGD participants had completed school-level education and $40 \%$ had been using hormones for 1 to 3 years. Five overlapping themes were identified: (1) reasons and motivations for hormone use; (2) accessibility and use of hormones; (3) side effects; (4) utilisation of healthcare services and (5) discontinuation of hormone use.

Conclusion Hormone use was common in our sample. Most received information on hormone therapy online and through their peer networks. A few study participants sought doctors' prescriptions for hormone therapy, but hormones were more likely to be bought from local private pharmacies or abroad through friends. This kind of self-medication is associated with a range of risks to the physical and mental health of transgender individuals. Incorporating information, education and communication about hormone therapy into existing health promotion interventions targeted to this population may help transgender people to make better informed choices.

\section{INTRODUCTION}

Transgender individuals are defined as "people whose gender identify and gender expression differ from their biological sex at birth'. They may be classified as 'male to female (MTF) transgender', that is, being assigned the male sex at birth but identifying as female or 'female to male (FTM) transgender', people being assigned the female sex at birth but identifying as male. ${ }^{12}$ However, there is a lack of consensus on a universally
Strengths and limitations of this study

This is a first study in Nepal to explore hormone use in transgender women.

- We invited participants from four of the seven provinces; therefore, our data include diverse views, covering all major ethnic groups.

- Despite Nepal being a conservative country, our focus group discussions and interviews generated rich data due to the active involvement of the participants in this research.

- Participants were invited through a local organisation that works for the transgender community; therefore, they may be more exposed to health and social issues than other transgender women.

- All researchers were male, which may have influenced the data collection.

accepted definition for individual who identify as transgender due to their diverse sexual orientation identities, attraction and behaviours. ${ }^{3}$ The ambiguity around definitions, combined with discrimination of transgender populations, reflects social taboos, which makes it difficult to estimate both the national and global prevalence of transgender identity. ${ }^{45}$ In the USA, studies suggest a prevalence of $0.4 \%$ to $0.6 \%$ for people who identify as transgender. ${ }^{6}$ Extrapolating the US prevalence proportion to the global population, Winter and colleagues ${ }^{5}$ have recently calculated that there is some 25 million trans people worldwide. The recent proposal to shift descriptive elements of transgender identity from 'mental health disorders' International Classification of Diseases (ICD-10) to 'sexual health categories' (ICD-11) may reduce stigma and serve as a useful instrument to estimate the size of this population. ${ }^{78}$

Health and well-being of transgender individuals in Nepal

Over the past decades, Nepal has witnessed significant legal reforms that affirm rights of its sexual and gender minority (SGM) populations including lesbian, gay, bisexual and transgender. The new Constitution of Nepal 
impressively recognised the rights of SGM as fundamental. ${ }^{9}$ Nepal acknowledges its transgender community by allowing a third category of 'others' (meaning gender other than male or female) on passports, citizenship certificates, electoral rolls and immigration forms. In addition, the Nepal Health Policy (2014) and other strategic documents such as the Nepal Health Sector Strategy 2016-2020 have enshrined several rights for SGM. ${ }^{11}{ }^{11}$ Yet, trans individuals in Nepal are often stigmatised or discriminated against while accessing health and social care services. Healthcare providers are poorly trained on issues of transgender. ${ }^{12}$ Furthermore, since society is generally conservative and condemns sexual orientation other than heterosexuality, it can be difficult for trans people to seek public services ${ }^{13}$ as they fear discrimination. ${ }^{12}$

The general health of transgender people is generally an under-research area. ${ }^{114}$ Until recently, most research on transgender populations in Nepal or other South Asian countries has focused on HIV, sexual behaviour and mental health, largely due to the disproportionate prevalence of HIV in transgender individuals. ${ }^{6}$ It has been estimated that transgender individuals in low-income and middle-income countries (LMICs) are 50 times more likely to be infected with HIV than other adults of reproductive age. ${ }^{15}$ This risk is also mirrored in the recent Integrated Biological and Behavioural Survey (IBBS) of Nepal which reported a higher HIV prevalence (11.5\%) in transgender individuals than other key populations such as injecting drug users, men who have sex with men (MSM) and sex workers. ${ }^{16}$ Similarly, a study with 232 Nepali trans people found that one-third had sexual intercourse with more than one sex partner per day. ${ }^{17}$ Utilisation of HIV Testing and Counselling services by Nepal's transgender population is also poor. ${ }^{18}$

Few studies report on sexual-orientation-based discrimination in public places experienced by Nepali trans individuals. For example, of the 139 transgender participants included in the Nepali IBBS study, 63\% experienced discrimination on the street or in parks. About one-third $(30 \%)$ experienced similar problems while seeking medical care ${ }^{16}$ Studies also documented that compared with MSM, a higher proportion of transgender individuals in Nepal experiences suicidal ideation (39.8\% vs $21.3 \%)$ or attempts suicide $(15.3 \%$ vs $6.4 \%),{ }^{19}$ while in the 2018 IBBS study, suicidal ideation among this group was as high as $41.7 \%{ }^{16}$ Global evidence suggests that transgender individuals have a higher prevalence of mental health problems. ${ }^{120-23}$ One US study, for example, with 230 transgender women, showed a high depression rate (63\% had Center for Epidemiological Studies Depression (CESD) 20 or higher) ${ }^{21}$ Anxiety levels are also commonly higher than in the general population, a systematic review reported prevalence rates in transgender populations ranging from $17 \%$ to $68 \% .^{24}$

To the best of our knowledge, none of the studies have examined the mental health status of Nepali transgender individuals using validated tools. In addition, tobacco and alcohol consumption are also widespread in the Nepali transgender population. ${ }^{17}$

\section{Hormone therapy by Nepali transgender women}

Transgender women, also known as trans women, may use different therapies to medically affirm their gender identity through feminisation of their appearance. Hormone therapy, injecting silicone, gender-affirmation surgery, breast augmentation, mechanical therapy for body or facial hair, and voice therapy are thought to be common. ${ }^{25-27}$ However, due to the high costs especially for gender-affirming surgery and the experience of healthcare-related stigma, many transgender people in LMICs cannot or would not seek gender-affirming care..$^{28-30}$

Hormone therapy induces the characteristics of the affirmed gender and reduces the characteristics of an individual's birth sex. Two classes of medications are most commonly used by trans women: (1) oestrogen therapies and (2) androgen-lowering hormone therapies. This is often in combination with progesterone therapies as a secondary agent to lower testosterone concentrations. ${ }^{31}$ For trans women, feminising treatments usually involve the use of oestrogen and an androgen blocker. ${ }^{32}$

The number of people using cross-sex hormone therapy worldwide has risen over the years. ${ }^{33}$ In Asia, studies in Thailand report 73\%-94\% hormone use among trans women. ${ }^{23435}$ The wider availability of hormones without prescription has most likely also resulted in an increased use in this population. In Nepal, 'hormones' are classified as a 'b' category medicine only available on prescription. This is in line with the framework developed by the Endocrine Society and the World Professional Association for Transgender Health (WPATH) ${ }^{36}$ In reality, only about one in five transgender individuals in Nepal were advised by a doctor to use hormones, while the overwhelming majority relied on non-medical advice. ${ }^{16}$ In practice, hormones are easily available from private pharmacists in Nepal without prescription. ${ }^{37}$

However, there is a dearth of research on the experience of hormone use or other therapies among transgender individuals in Nepal. Studies from other geographical settings on hormone use by transgender individuals have yielded mixed outcomes. For example, a study in France found a positive effect of hormone therapy on their quality of life (QoL).$^{38}$ However, such QoL studies do not exist in Nepal. Emerging evidence shows that hormone use is associated with numerous health risks such as venous thromboembolism, elevated liver enzymes, gallstones, decrease in haemoglobin, low sexual desire, reduction in facial/body hair, increased rate of myocardial infarction or depression. ${ }^{31} 3940$ Where hormones are difficult to access with a prescription, transgender population seek and use hormones in less safe ways. For example, in Chicago, $71 \%$ of trans women reported obtaining hormones from a non-medical source in the past year ${ }^{41}$; similarly, $58 \%$ of trans women in Virginia reported ever having used non-prescribed hormones. ${ }^{42}$ Although the literature on needle sharing 
in trans populations is sparse, sharing needles to inject hormones could increase the risk of acquiring infectious diseases. ${ }^{43}$ The degree of interactions between hormones and antiretroviral therapy in the transgender population is another area of research that currently lacks sufficient evidence. $^{32}$

Media reports suggest that trans women in Nepal also use hormones bought in private pharmacies. ${ }^{44} 45$ There is poor regulation and monitoring of many drugs dispensed through private pharmacies, which make them easily available without a prescription, but there is a notable lack of published research on hormone use. ${ }^{12}$ Evidence on what type of hormones they take, how these are consumed (oral or injection), who prescribes them and what are the side effects experienced by transgender individuals from these hormones are still not known. The IBBS survey of $\mathrm{Nepal}^{16}$ reported that about a quarter $(24 \%$; 33 of 139 participants) of transgender individual were using hormones, mostly as their own choice or suggested by peers. The self-administration of hormones may result in a considerable health risk to this subgroup in the population. Although the transgender population constitutes a small proportion of the total population, it is imperative to understand their healthcare needs and their risktaking behaviours to achieve universal health coverage as envisioned in the Sustainable Development Goals. Against this backdrop, this study explored (1) hormone use among trans women, (2) types of hormones used and how they are consumed, and (3) side effects experienced after hormone use. Findings from this study may help to develop health promotion strategies that could improve their access to healthcare and enhance their experiences of using health services.

\section{METHODS AND MATERIALS \\ Data collection}

In September 2016 to March 2017, we carried out a qualitative study comprising eight focus group discussions (FGDs) with self-identified trans women aged 18 years and older. Participants did not have to be on hormones at the time of the study. To capture diverse views, the FGDs were carried out in four of the seven different provinces (table 1). The research team selected these provinces purposively to represent the different geographical areas (eg, hill, terai, urban, rural) of the country. The closest to

Table 1 Number of FGD and participants by study areas

\begin{tabular}{lr}
\hline Participants by district & N (\%) \\
\hline Kathmandu (5 FGD) & $39(62.9)$ \\
Kaski (1 FGD) & $7(11.3)$ \\
Banke (1 FGD) & $8(12.9)$ \\
Sunsari (1 FGD) & $8(12.9)$ \\
Total participants & $62(100)$ \\
\hline
\end{tabular}

FGD, focus group discussion. a national record is data published in 2019 by Poudel and colleagues ${ }^{46}$ who estimated 18704 to 24216 transgender individuals for 2016, without specifying the proportion of trans women or men. The number of participants in the FGDs ranged from seven to nine persons. Additionally, participants who did not want to share their views in a group setting were offered an in-depth interview, resulting in three in-depth interviews. We also organised six key informant interviews (KIIs) with relevant stakeholders, including representatives working in non-governmental organisations (NGOs) supporting the SGM population in Nepal, a district health officer, an HIV programme coordinator and two KIIs were with trans people.

We invited potential research participants using a convenience sampling strategy in close collaboration with an NGO called Blue Diamond Society (BDS), which is working for the SGM population in Nepal. BDS invited participants for the FGDs through its network of regional coordinators. The coordinators and local outreach workers invited local trans women through word of mouth. Due to the stigma attached to being transgender, other more public ways of inviting participants were deemed to be inappropriate. All FGDs and interviews were conducted in Nepali by PRR and SRN who are native Nepali speakers and experienced qualitative researchers on sensitive health issues. Interviews took place in a location agreed with the participants, usually NGO offices. With the prior permission from the participants, the FGDs and interviews were audio recorded. The researchers made short field notes of non-verbal behaviour during the qualitative data collection. Most of our FGDs lasted between 1 and 2 hours, whereas interviews took between 45 min and 1 hour.

\section{FGD and interview facilitation tools}

Based on the literature, the research team, in collaboration with key stakeholders, drafted a discussion guide ${ }^{47}$ to facilitate FGDs $^{48}$ and interviews. ${ }^{49}$ The FGD guide included knowledge of hormones, first experience with hormone, administration of hormones, source of injection paraphernalia and who injects, experience of side effects and its management (copy available from first author on request). Prior to the discussion, demographic characteristics such as age, education, ethnicity, employment and duration of hormone use were collected from each FGD participant. The questions included in the guide were pretested in a similar $\mathrm{FGD}^{50}$ with trans women in Kathmandu. This pilot resulted in minor changes to the final discussion guides, but as these were not very different from the pilot, its findings were included in our analysis. The FGD guide was used in all FGDs as a starting point and the interview guide was adjusted for each KII depending on their background. Thus, the KII guideline included questions around hormone use, the uptake of healthcare services, specific programme targeting these population and programmatic recommendations. 


\section{Data organisation and analysis}

We transcribed $^{51}$ the original recordings before translation into English by a Nepali social scientist, who was trained for this study. PRR and SRN (both native Nepali speakers) independently reviewed the transcribing and translating. Transcripts were crossed checked with original recordings. Any disagreements were discussed in detail between PRR and SRN for appropriate translation. Each transcript had a cover note describing the interviews, settings, how the discussion had been any, any differences from other interviews, particular incidents, environments and a reflection on the issues identified in the session. The data were then organised through NVivo V.11. ${ }^{52}$ As part of the thematic analysis, PRR read and coded all transcripts and ERvT and SRN did the same for half of the transcripts each and acted as second independent coders. A thematic approach was followed for data analysis. ${ }^{53}$ In the spirit of qualitative research, any differences between the first and the second coder were discussed in the team until consensus was reached. Relevant quotes are presented to illustrate the key themes. ${ }^{54}$ We followed Consolidated criteria for Reporting Qualitative research (COREQ) checklist to report FGD and interview data. ${ }^{55}$

\section{Ethical consideration}

Our study was conducted in compliance with human rights and ethical standards required from studies on sensitive issues. ${ }^{56}$ Written informed consent was obtained privately from all research participants prior to the FGDs and interviews. Through an information sheet in Nepali, participants were provided with enough information about the study purpose and procedure, voluntary participation, confidentiality, risk and benefits to the participants, complaint procedure and so on. Participants' travel costs were reimbursed, but no financial incentives were provided.

\section{Patient public involvement}

Patient public involvement is a relatively new concept in Nepal. However, we involved lay experts (=trans women) and relevant key stakeholders from the conceptualisation of this study. Our data collection tools and information sheet were piloted through an FGD with seven participants to ensure that they are inclusive and comprehensive. We will also engage them in disseminating results of this study, particularly their contribution while developing research factsheets in plain language and communicating them to transgender individuals will be very valuable.

\section{RESULTS}

\section{Characteristics of participants}

Most FGD participants were young (mean age 23.06 \pm 3.9 years) and the majority (55\%) completed grade 6 to high school level. About one-third had completed secondary education, in Nepal this is called School Leaving Certificate (equivalent of high school in the USA or secondary school in the UK). In terms of ethnicity, Brahmin/Chhetri
Table 2 Characteristics of focus group discussion participants

\begin{tabular}{|c|c|}
\hline $\begin{array}{l}\text { Sociodemographic } \\
\text { characteristics }(n=62)\end{array}$ & $\mathbf{N}(\%)$ \\
\hline Age $($ mean $\pm S D)$ & $23.06 \pm 3.9$ years \\
\hline \multicolumn{2}{|l|}{ Ethnicity $^{*}$} \\
\hline Brahmin/Chhetri & 26 (41.9) \\
\hline Newar & $8(12.9)$ \\
\hline $\begin{array}{l}\text { Janajati (including Tharu/ } \\
\text { Chanduari) }\end{array}$ & $25(40.3)$ \\
\hline Dalit & $3(4.8)$ \\
\hline \multicolumn{2}{|l|}{ Education } \\
\hline Up to primary (up to 5th grade) & $9(14.5)$ \\
\hline Up to school level (6th to SLC) & $34(54.8)$ \\
\hline Higher (above SLC) & 19 (30.6) \\
\hline \multicolumn{2}{|l|}{ Occupation } \\
\hline Bar dancer & $12(19.4)$ \\
\hline Waiter & $14(22.6)$ \\
\hline Business & $4(6.5)$ \\
\hline NGO/development worker & $4(6.5)$ \\
\hline Sex worker & $3(4.8)$ \\
\hline Modelling/fashion & $1(1.6)$ \\
\hline Unemployed & $24(38.7)$ \\
\hline \multicolumn{2}{|l|}{ Currently living with } \\
\hline Friends & $24(38.7)$ \\
\hline Family & $24(38.7)$ \\
\hline Alone & $14(22.6)$ \\
\hline \multicolumn{2}{|l|}{ Time at current address } \\
\hline$<6$ months & $15(24.2)$ \\
\hline$>6$ months & $47(75.8)$ \\
\hline \multicolumn{2}{|l|}{ Duration of hormone use } \\
\hline$<6$ months & $9(14.5)$ \\
\hline $1-3$ years & 25 (40.3) \\
\hline$>3$ years & $18(29.0)$ \\
\hline $\begin{array}{l}\text { Previously used but now } \\
\text { stopped using }\end{array}$ & $10(16.1)$ \\
\hline
\end{tabular}

*Ethnicity recoded in line with Census of Nepal.

NGO, non-governmental organisation; SLC, School Leaving Certificate.

and Janajati groups represented $82 \%$ of our FGD sample, and Dalits represented 5\%. This suggests an under-representation of participants from Dalit communities in our study compared with the total population in the latest census. ${ }^{57}$ About 39\% ( $\left.\mathrm{n}=24\right)$ lived with friends; $42 \%$ $(n=26)$ worked in restaurants/bars and $40 \%(n=25)$ had been using hormones for 1 to 3 years (table 2). Although sex and sexuality are considered as taboo subjects and not discussed openly in most Nepali families, our participants were actively engaged during the research. More people 
were invited than attended on the day, but none withdrew during the FGDs or interviews.

We identified five partly overlapping themes: (1) reasons and motivations for hormone use; (2) accessibility and use of hormones; (3) side effects; (4) participants' health-seeking behaviours overlapping and (5) discontinuation of hormone use. Each theme is discussed below and is supported and illustrated by relevant quotes.

\section{Reasons and motivations for hormone use}

The overarching reason for using hormones was to affirm to a more feminine gender. Many wanted to look female. In the following quote, 'Diane' refers to contraceptive birth control pills to make one's skin and hair less greasy:

...I heard about it [=hormone] from my friends. First, I searched on YouTube about how a person whose appearance is like a boy can become a girl .... There are both good and bad effects. But since we live only once we all want to be beautiful and fairer, isn't it? And then I started using 'Diane'. That is from Thailand. (FGD1, Kathmandu)

Almost all our FGD participants stated that 'friends' are the main sources of information about hormones, as the quote above already suggested. Some participants, particularly from Kathmandu, had acquired information about hormones through the internet, mainly YouTube. A few participants also mentioned organisations working for transgender populations (without naming them explicitly) as a source of information on hormones.

Non-prescribed hormone use appears to be common and most participants started using hormones after encouragement from their friends:

We do [=use hormones] on the basis of friends... Friends said that breasts will increase if we use this. (In-depth interview 3, Kathmandu)

The key motive for hormone use was to get a feminine look. Most participants believed that hormones help them change their physical appearance. Some started using hormones only after they saw positive changes to their friends, as exemplified by this quote:

First of all, I saw my friends using it [=hormone]. After seeing good effects on them, I also wanted to use it ... I am still using it. I used 'Diane'. (FGD3, Kathmandu)

Friends did not have to be close by, or even in Nepal, some referred to friends abroad:

I have many friends in India. They are used to taking hormone. After using hormone, this [=pointing to her breast] increased. Then I also started having the desire to use hormone. Then my friend said, "I know about this [=hormone], you can get it here." Then that friend took me and I bought it. (In-depth interview 2, Kathmandu)

\section{Access to hormone, types, intake and doses}

Hormones were commonly taken as injections or orally. Some participants named several brands/trade names of hormone (pills and injectable); however, most were unware of the types of hormones they were taking. One participant stated:

...I do not know the name of hormone. My friends bring them [=hormones] for me. I do not normally look at the name. (In-depth interview 1, Kathmandu)

When asked about the places to buy/access these hormones, it was found that local pharmacies were the popular choice for most. Accessing hormones from NGOs was also reported but participants did not want to share about NGOs in detail. Some even travelled abroad to buy these hormones, with Thailand as the preferred destination. One FGD participant said, while speaking about visiting pharmacists in Thailand, when we ask for a specific hormone by name they simply sell it to us.

There was agreement among participants that hormones from abroad are of a better quality than the ones available locally. There was a notion among our participants that hormones from overseas acted faster; therefore, many got friends to buy these when they travelled overseas:

...it [=hormone from Bangkok] makes our body soft, veins are not visible, our body feels soft like those of girls. The medicine that we get here also works but takes longer to work. (FGD5, Kathmandu)

Or

Chest development is faster by the medicine from Bangkok than here. (FGD1, Kathmandu).

Hormones from abroad were also considered as creating effects that lasted longer:

We keep on bringing from there [=overseas] till we become beautiful. [Laughing] We bring hormones that will be sufficient for many years at a time. (FGD3, Kathmandu)

Our findings suggest that trans women in Nepal use hormone in an improper way, including using too many hormones at the same time for the sake of instant outcomes. They seemed not to follow guidance regarding recommended doses, for example, one participant stated:

... women who use hormone for family planning take one hormonal tablet in a day while TG [=transgender] uses two in the morning and two in the evening which will definitely have an effect. So, you have to provide information about this [=hormone]. (FGD8, Banke)

Without a proper prescription, self-medication leads to 'common sense decisions' about the timing and dose of the hormone:

We used to take two tablets in the morning and two in the evening when our chests were not large. But now, 
since our chest has increased and as we felt that it has some disadvantages also then I have started taking just one in a day. (FGD6, Kaski)

While stigma and fear of the hormones being discovered in one's belongings, some did not take hormone with them when visiting family (especially in rural areas):

I do not carry hormone with me when I go home... I do not take it when I stay at home. I take it again after I come here. (FGD7, Sunsari)

\section{Self-reported side effects}

Frequently reported side effects of hormones were headache, decreased sexual desire, spots (acne) on cheeks and forehead, lost appetite, chest pain, vomiting, weight gain, shortness of breath, itchy, dizziness, sleepy, feeling weak, feeling angry, hair falling out, gain in thigh and buttock muscles. Most argued that these hormones/chemicals have no benefits to their health, for example, one FGD participant said:

There is definitely no benefit. This is just for beauty. (FGD2, Kathmandu)

Some participants argued that hormone use can cause a range of serious diseases, such as diabetes, cancers, high blood pressure and high cholesterol; therefore, it can impact on their mental health well-being.

... we can start thinking that we are victims of depression. Hormone makes us monotonous, we do not like to work, we do not feel sleepy but sometimes we feel too sleepy, we feel tired, we like to eat too much, we like to sleep all the time, body becomes hot, sometimes we feel too hot and sometimes we feel too cold. (FGD6, Kaski)

This was also reflected in a different FGD:

We feel very weak ... feels like vomiting, tiredness, spots on face and there is risk of diabetes, paralysis, blood cancer and breast cancer in the long run. (FGD2, Kathmandu)

\section{Utilisation of healthcare services}

Utilisation of healthcare services to explore about hormones or seek help for side effects of hormone use was very poor. Although most visited private pharmacies for injecting hormones, discussion around types of hormones used, side effects or other health issues was very poor. The decision to start using oral pills seems to be largely based on encouragements from their peers.

Talking about injectable, we go to medical [=pharmacy] and get injected ...but we did not take hormone [=oral pills] by consulting doctors; we took it by following our friends. (FGD1, Kathmandu)

Almost all participants noted that they feel shy and generally hesitate to discuss these matters with doctors or nurses. Lack of user-friendly services at the healthcare centres was frequently reported as a barrier:

It is very shameful when we have to go for check-up. We rather die than going for a check-up. There are females [=healthcare care worker] and we have a lot of problems. (FGD4, Kathmandu)

... No, I did not go anywhere. If I do check-up and if they show serious problem then ... I had gone to teaching hospital once. I had to open my clothes for video $\mathrm{x}$-ray. There were boys also. I felt very shy thinking that my breasts will be on display. (Participant, FGD3, Kathmandu)

Some stressed that there are no specialist healthcare professionals on transgender health in Nepal.

... there are no any specialists here [ $=$ in Nepal]. When we go to Bangkok a number of times, somehow specialists are there. There are shops and we get injectable there and return back. (FGD1, Kathmandu)

However, there were a few participants who had consulted a health professional when they had problems:

I explained my problem and she recommended something. After that nothing happened to me $[=$ i.e. there was no reaction to be seen]. Then I asked an older friend and started using 'Sunaulo Gulab' [=an oral contraceptive pill in Nepal] by myself. After that I became too weak again and I went to the endocrinologist of Bir Hospital and did some tests. And then I became well. (FGD1, Kathmandu)

\section{Discontinuation of hormone use}

Participants have no any fixed plan or schedule to stop using hormones. The decision to discontinue hormone use is often made abruptly by users. Participants reported that having side effects (experienced or perceived) are the main reasons for discontinuation of hormones.

Actually, I used to take hormone before as well when I used to work in the fancy store. I used to go as a boy by wearing a jacket. It [=breast] was not too large. It was this much [showing with hand]. I used to feel shy though it [=breast] was small, so I used to wear big jackets and go for work. Then I came here and some said that hormone causes this and some said hormone causes that so I stopped using hormone. Then breasts also started decreasing as I stopped using hormone. (FGD7, Sunsari)

Others reacted to the views and experiences of people like them:

... I used that [=hormone] for about 2-3 years. Then people said that hormone caused sugar [=diabetes], thyroid and others. Also, one of my older friends who has been using hormone for long suffered from diabetes, thyroid problems, so I stopped using that [=hormone]. (In-depth Interview 2, Kathmandu) 
Some had to discontinue hormone use temporarily when their stocks ran out. This was particularly challenging to those users who bought hormones overseas. Discontinuation during home visit was also reported.

... I had left using hormone in the middle but again [=name removed] brought hormone from overseas some days ago, so I started using that. That $[=$ hormone] has finished now and there was no one who would go Thailand. (FGD4, Kathmandu)

Others mentioned not taking hormones when or they are ill:

We leave taking it [=hormone] when we are not well and we use it when we are well. (FGD8, Banke)

\section{DISCUSSION}

This is the first study to explore hormone use in Nepali trans women. The study identified five key themes around hormone use ranging from reasons and motivations for using, accessibility, side effects and healthseeking behaviours to stopping to take hormones. Overall, the peer network of the trans woman and the internet media, particularly YouTube, played a significant role in disseminating information about hormones to the transgender population, of course, this is not necessarily medically correct information on hormones. Moreover, users require a good level of health literacy in English to comprehend most of the online health information. Clark and colleagues found that for trans women in the USA, having a greater number of hormone-using networks and using the internet to find transgender friends affected the likelihood of misusing hormones in different ways. ${ }^{58}$ Social science research has suggested that network dynamics can affect the behaviour of trans women regarding hormone use. ${ }^{5859}$

In Nepal, access to information about hormones and their use through healthcare providers is alarmingly poor. Trans women's decision to take hormones is largely influenced by their peers and their self-medication is unsupervised, suggesting they are unaware about the types of the hormones they use, their side effects or required doses. Indeed, seeking sensitive information on sexuality, reproductive health or hormones from peers is not unique to Nepal and other Asian countries. ${ }^{6061}$ For example, an earlier study in Lao found that as few as one in eight of those using hormones sought advice from medical professionals, instead most often relying on friends for information about hormones. ${ }^{61}$

The most frequently reported generic motives for using hormones were looking more feminine (ie, developing breasts) and beautiful. Participants generally had a poor knowledge of hormones and many reported side effects from hormone use affecting their mental well-being. Hormones should only be prescribed by an authorised medical professional ${ }^{37}$; however, we found that accessing hormones through local pharmacies is common. A study in India also reported an unwillingness among qualified medical practitioners to prescribe hormone therapy forcing transgender individuals to self-administer hormones. ${ }^{62}$ There is evidence that utilisation of healthcare professionals by transgender persons is associated with their reduction of risk behaviours. ${ }^{63}$

We found that some trans women buy hormones abroad, primarily from Thailand or India; unfortunately, there are no studies on side effects of hormone use in South Asia. The notion that one can buy better 'quality hormones' abroad influenced their decision to use these particular ones. There may be risks to using non-prescribed hormones such as not recognising side effects nor seeking medical help when needed. This may result in non-adherence to the recommended treatment regime since obtaining medicines remotely involve higher costs, travel and legal issues. The WPATH recommends that hormone therapy should only be initiated once a psychosocial assessment has been completed and informed consent reviewing the risks and benefits of starting therapy has been obtained and transgender-specific guidelines are available for healthcare providers. ${ }^{36}$

Transgender individuals have many health priorities on top of sexual and reproductive health and HIV prevention. ${ }^{64}$ They may face mental health issues due to the side effect of hormone use as well as social discrimination. Transgender individuals feel there is discrimination against them in government health centres and a lack of user-friendly or transgender specialist services. All these factors drive them to seek services from the private health sector or overseas which many in Nepal can ill afford. This calls for capacity building (eg, specialised training, quality services) of all health workers and particularly health professionals working for the transgender/ SGM population. Capacity building activities should also include non-clinical staff such as receptionists or those serving at ticket counters as they are the front-line contact staff. These activities may help to ensure non-discriminatory behaviours when providing services to transgender or other sexual minority populations. ${ }^{12}$

Globally, individuals who identify as transgender are considered as a 'key population' for the HIV response due to their high-risk sexual behaviours. ${ }^{61517}$ Programmes in Nepal are also HIV and sexual transmitted infection (STI) centric and ignore the area of hormone use in the transgender population. We suggest that Nepali trans women's low knowledge around proper dosing of hormones and intermittent access to self-prescribed hormone is problematic. If interventions provide training to existing staff on hormones and its safe use, these staff can easily cascade proper information on hormones to their peers just like they are currently doing for HIV and STI prevention, treatment and care. For example, there are out-reach workers, community mobilisers and peer educators who provide HIV and STI-related services to the transgender population. We propose that these health workers are also trained in providing hormone counselling to this population. In Canada, for example, the 
Trans Health Connection project initiated in 2011 offers in-depth training to primary care providers on different issues such as social and medical transition; administration of hormones and preventative care and supporting mental health and well-being through counselling or group work. ${ }^{30}$ In Nepal, the existing strategic behavioural and communication materials, providing information on HIV/STI targeting transgender individuals, could serve as a platform for providing information on hormones.

\section{Strengths and limitations}

Despite Nepal being a conservative country where sex and sexuality are not openly discussed, most participants actively engaged during the FGDs and interviews. Consequently, our data are rich and include diverse views of our participants. Offering in-depth interviews to those participants who were not willing to participate in the FGD also made our data inclusive. As we invited the participants through a local NGO that works for transgender community, we acknowledge that our participants may be more exposed to health and social issues than the rest of transgender individuals. We might have also excluded transgender people who did not want to expose their status to this organisation's network. Although we conducted our FGDs in different geographical locations, we may have missed the views of trans women elsewhere in Nepal who have different sociocultural or behavioural characteristics than our participants, but we managed to cover all major ethnic groups. Although we invited participants regardless of their previous exposure to hormones, all had used or were using some types of hormones. Finally, all researchers were male in this study, which may have influenced the data collection.

\section{CONCLUSION}

Hormone therapy is used by some Nepali trans women to medically affirm their gender identity through feminisation of their appearance. Peer networks and the internet are key sources for learning about hormones and for disseminating information to this transgender population. Very few in our sample sought doctors' advice and prescription when accessing hormone therapy as also reported by the 2018 IBBS survey of Nepal. ${ }^{16}$ Our findings suggest that hormones are more likely to be bought from either local private pharmacies or abroad through friends; this kind of self-medication of hormones in trans women bring with it a range of risks to the physical and mental health of transgender individuals. Existing interventions targeting transgender individuals in Nepal may act as a platform when providing information, education and communication around hormone therapy. The latter needs to be embedded into existing services to support trans people and offer them informed choice in gender-affirming care. More research is needed into the nature of self-medication through hormones and their health and side effects; these studies need a longitudinal element and include the measurement of QoL.
Twitter Pramod R Regmi @iresearch

Acknowledgements We would like to thank all our participants for their active participation in our research. We also thank the reviewers for their insightful comments on the initial submission and we like to thank the BDS for its support.

Contributors PRR and SRN conceived the study. SRN coordinated with relevant stakeholders in Nepal and led the data collection, transcription and translation process. PRR organised the data through NVivo and analysed the data. ERvT, SRN and SBM acted as second coders. PRR wrote the first draft of the manuscript. ERvT, SRN and SBM helped with the revision of the manuscript. All authors have agreed on the final version.

Funding This study was supported by a seed-corn funding from the Faculty of Health and Social Sciences, Bournemouth University, UK.

Competing interests None declared.

Patient consent for publication Not required.

Ethics approval Our study protocol was approved by Bournemouth University (Ref. 12251) and the Nepal Health Research Council (Ref. 188/2016).

Provenance and peer review Not commissioned; externally peer reviewed.

Data availability statement Data are available on reasonable request.

Open access This is an open access article distributed in accordance with the Creative Commons Attribution Non Commercial (CC BY-NC 4.0) license, which permits others to distribute, remix, adapt, build upon this work non-commercially, and license their derivative works on different terms, provided the original work is properly cited, appropriate credit is given, any changes made indicated, and the use is non-commercial. See: http://creativecommons.org/licenses/by-nc/4.0/.

\section{REFERENCES}

1 Reisner SL, Poteat T, Keatley J, et al. Global health burden and needs of transgender populations: a review. Lancet 2016;388:412-36.

2 Guadamuz TE, Wimonsate W, Varangrat A, et al. HIV prevalence, risk behavior, hormone use and surgical history among transgender persons in Thailand. AIDS Behav 2011;15:650-8.

3 World Health Organization. HIV and young transgender people. Geneva: World Health Organization, 2015.

4 Collin L, Reisner SL, Tangpricha V, et al. Prevalence of transgender depends on the "case" definition: a systematic review. J Sex Med 2016;13:613-26.

5 Winter S, Diamond M, Green J, et al. Transgender people: health at the margins of Society. Lancet 2016;388:390-400.

6 Meerwijk EL, Sevelius JM. Transgender population size in the United States: a meta-regression of population-based probability samples. Am J Public Health 2017;107:e1-8.

7 Cavalin C. Gender and health: between nomenclatures and continuums. Lancet 2016;388:2601.

8 Robles R, Fresán A, Vega-Ramírez H, et al. Removing transgender identity from the classification of mental disorders: a Mexican field study for ICD-11. Lancet Psychiatry 2016;3:850-9.

9 Regmi PR, van Teijlingen E. Importance of health and social care research into gender and sexual minority populations in Nepal. Asia Pac J Public Health 2015;27:806-8.

10 Ministry of Health. National health policy. Kathmandu: Ministry of Health, 2014.

11 Ministry of Health and Population. Nepal health sector strategy 20152020. Kathmandu: Ministry of Health and Population, 2015.

12 United Nations Development Programme. Being LGBT in Asia: Nepal country report. Bangkok: UNDP, 2014.

13 Wilson E, Pant SB, Comfort M, et al. Stigma and HIV risk among Metis in Nepal. Cult Health Sex 2011;13:253-66.

14 Lo S, Horton R. Transgender health: an opportunity for global health equity. Lancet 2016;388:316-8.

15 Baral SD, Poteat T, Strömdahl S, et al. Worldwide burden of HIV in transgender women: a systematic review and meta-analysis. Lancet Infect Dis 2013;13:214-22.

16 National Centre for AIDS and STD Control (NCASC). Integrated biological and behavioural surveillance (IBBS) survey among men who have sex with men and transgender, round 2. Kathmandu: Ministry of Health and Population, NCASC, 2018.

17 Bhatta DN. HIV-related sexual risk behaviors among male-to-female transgender people in Nepal. Int J Infect Dis 2014;22:11-15.

18 Shrestha R, Philip S, Shewade HD, et al. Why don't key populations access HIV testing and counselling centres in Nepal? Findings based on national surveillance survey. BMJ Open 2017;7:e017408. 
19 Kohlbrenner V, Deuba K, Karki DK, et al. Perceived discrimination is an independent risk factor for suicidal ideation among sexual and gender minorities in Nepal. PLoS One 2016;11:e0159359.

20 Nemoto T, Bödeker B, Iwamoto $\mathrm{M}$, et al. Practices of receptive and insertive anal sex among transgender women in relation to partner types, sociocultural factors, and background variables. AIDS Care 2014:26:434-40.

21 Nuttbrock L, Bockting W, Rosenblum A, et al. Gender abuse, depressive symptoms, and HIV and other sexually transmitted infections among male-to-female transgender persons: a three-year prospective study. Am J Public Health 2013;103:300-7.

22 Pitts MK, Couch M, Mulcare H, et al. Transgender people in Australia and New Zealand: health, well-being and access to health services. Fem Psychol 2009;19:475-95.

23 Clark TC, Lucassen MFG, Bullen P, et al. The health and well-being of transgender high school students: results from the New Zealand adolescent health survey (Youth'12). J Adolesc Health 2014;55:93-9.

24 Millet N, Longworth J, Arcelus J. Prevalence of anxiety symptoms and disorders in the transgender population: a systematic review of the literature. Int J Transgend 2017;18:27-38

25 Wansom T, Guadamuz TE, Vasan S. Transgender populations and HIV: unique risks, challenges and opportunities. J Virus Erad 2016;2:87-93.

26 Kalra S. The eunuchs of India: an endocrine eye opener. Indian J Endocrinol Metab 2012;16:377.

27 Sevelius JM. Gender affirmation: a framework for conceptualizing risk behavior among transgender women of color. Sex Roles 2013;68:675-89.

28 White Hughto JM, Murchison GR, Clark K, et al. Geographic and individual differences in healthcare access for U.S. transgender adults: a multilevel analysis. LGBT Health 2016;3:424-33.

29 White Hughto JM, Reisner SL, Pachankis JE. Transgender stigma and health: a critical review of stigma determinants, mechanisms, and interventions. Soc Sci Med 2015;147:222-31.

30 Rotondi NK, Bauer GR, Scanlon K, et al. Nonprescribed hormone use and self-performed surgeries: "do-it-yourself" transitions in transgender communities in Ontario, Canada. Am J Public Health 2013;103:1830-6.

31 T'Sjoen G, Arcelus J, Gooren L, et al. Endocrinology of transgender medicine. Endocr Rev 2019;40:97-117.

32 Radix A, Sevelius J, Deutsch MB. Transgender women, hormonal therapy and HIV treatment: a comprehensive review of the literature and recommendations for best practices. J Int AIDS Soc 2016;19:20810.

33 Leinung MC, Urizar MF, Patel N, et al. Endocrine treatment of transsexual persons: extensive personal experience. Endocr Pract 2013;19:644-50.

34 Gooren LJ, Sungkaew T, Giltay EJ. Exploration of functional health, mental well-being and cross-sex hormone use in a sample of Thai male-to-female transgendered persons (kathoeys). Asian J Androl 2013;15:280-5.

35 Winter S. Thai transgenders in focus: demographics, transitions and identities. Int J Transgend 2006;9:15-27.

36 Unger CA. Hormone therapy for transgender patients. Trans/ Androl Urol 2016;5:877-84.

37 World Health Organization. Medicines in health care delivery. New Delhi: World Health Organization, 2015

38 Gorin-Lazard A, Baumstarck K, Boyer L, et al. Is hormonal therapy associated with better quality of life in transsexuals? A crosssectional study. J Sex Med 2012;9:531-41.

39 Asscheman $\mathrm{H}$, T'Sjoen G, Lemaire A, et al. Venous thromboembolism as a complication of cross-sex hormone treatment of male-to-female transsexual subjects: a review. Andrologia 2014:46:791-5

40 Feldman J, Brown GR, Deutsch MB, et al. Priorities for transgender medical and healthcare research. Curr Opin Endocrinol Diabetes Obes 2016;23:180-7.

41 Garofalo R, Deleon J, Osmer E, et al. Overlooked, misunderstood and at-risk: exploring the lives and HIV risk of ethnic minority maleto-female transgender youth. J Adolesc Health 2006;38:230-6.
42 Xavier J, Honnold J, Bradford J. The health, health-related needs, and lifecourse experiences of transgender Virginians: Virginia transgender health Initiative study statewide survey report Richmond, VA: Virginia Department of Health, Division of Disease Prevention through the Centers for Disease Control and Prevention, 2007.

43 Poteat T, Malik M, Scheim A, et al. HIV prevention among transgender populations: knowledge gaps and evidence for action. Curr HIVIAIDS Rep 2017;14:141-52.

44 Manandhar S. In Nepal, transgender people spend Hefty sums, risk health problems to manifest their gender identities. Global Press Journal, 2014.

45 Shrestha A. Transgenders on male-to-female hormonal therapy experiencing its adverse health effects. The Himalayan Times, 2018.

46 Poudel T, Gupta S, Bhattarai R, et al. Mapping and size estimation of key populations on HIV surveillance in Nepal. Journal of Gandaki Medical College-Nepal 2019;12:39-42.

47 Hennink MM. International focus group research: a handbook for the health and social sciences. Cambridge: Cambridge University Press, 2007.

48 van Teijlingen E, Pitchforth E. Focus group research in family planning and reproductive health care. J Fam Plann Reprod Health Care 2006;32:30-2.

49 Britten N. Qualitative research: qualitative interviews in medical research. BMJ 1995;311:251-3.

50 van Teijlingen ER, Hundley V. The importance of pilot studies. Social Research Update 2010;35:49-59.

51 McLellan E, MacQueen KM, Neidig JL. Beyond the qualitative interview: data preparation and transcription. Field methods 2003;15:63-84.

52 Bazeley P, Jackson K. Qualitative data analysis with NVivo. London: Sage, 2013

53 Forrest Keenan K, van Teijlingen E, Pitchforth E. The analysis of qualitative research data in family planning and reproductive health care. J Fam Plann Reprod Health Care 2005;31:40-3.

54 Sandelowski M. Focus on qualitative methods. The use of quotes in qualitative research. Res Nurs Health 1994;17:479-82.

55 Tong A, Sainsbury P, Craig J. Consolidated criteria for reporting qualitative research (COREQ): a 32-item checklist for interviews and focus groups. Int J Qual Health Care 2007:19:349-57.

56 Regmi PR, Aryal N, Kurmi O, et al. Informed consent in health research: challenges and barriers in Low-and middle-income countries with specific reference to Nepal. Dev World Bioeth 2017;17:84-9.

57 Central Bureau of Statistics. Population monograph of Nepal, volume II, social demography. Kathmandu: National Planning Commission, Central Bureau of Statistics, 2014

58 Clark K, Fletcher JB, Holloway IW, et al. Structural inequities and social networks impact hormone use and misuse among transgender women in Los Angeles County. Arch Sex Behav 2018:47:953-62.

59 Nemoto T, Bödeker B, Iwamoto M. Social support, exposure to violence and transphobia, and correlates of depression among male-to-female transgender women with a history of sex work. Am J Public Health 2011;101:1980-8.

60 Regmi PR, van Teijlingen ER, Simkhada P, et al. Dating and sex among emerging adults in Nepal. J Adolesc Res 2011;26:675-700.

61 Winter S, Doussantousse S. Transpeople, hormones, and health risks in Southeast Asia: a Lao study. Int J Sex Health 2009;21:35-48.

62 Singh Y, Aher A, Shaikh S, et al. Gender transition services for Hijras and other male-to-female transgender people in India: availability and barriers to access and use. Int $J$ Transgend 2014:15:1-15.

63 Sanchez NF, Sanchez JP, Danoff A. Health care utilization, barriers to care, and hormone usage among male-to-female transgender persons in New York City. Am J Public Health 2009;99:713-9.

64 Bockting W, Coleman E, Deutsch MB, et al. Adult development and quality of life of transgender and gender nonconforming people. Curr Opin Endocrinol Diabetes Obes 2016;23:188-97. 